\title{
Evaluation of Mass Transfer and Interfacial Area Correlations in Direct Contact Packed-Bed: Comparison of Correlations
}

\author{
Mahyar Abedi, Parnab Saha, Xu Tan, James F. Klausner, Andre Benard \\ ${ }^{1}$ Michigan State University \\ East Lansing, Michigan, USA \\ abedimah@msu.edu; sahaparn@msu.edu; tanxu@msu.edu; jfk@msu.edu; benard@msu.edu
}

\begin{abstract}
A direct contact condenser with a packed bed is a highly efficient component of air/vapor mixture condensation systems. A mathematical model is crucial to predict the performance of the condenser but existing models contain empirical correlations with limited or undefined range of validity. In this research, a comparison between several mass transfer coefficient correlations for air/vapor and liquid and the interfacial area is performed. An experimental setup has been built and tested for validation purposes. The boundary conditions and experimental data have been compared with the prediction from various listed models. It is concluded from the study that the Onda and Billet correlations are compatible with most of the results obtained from the experimental study.
\end{abstract}

Keywords: direct contact, condensation, packed bed, mass transfer co-efficient.

\section{Nomenclature}

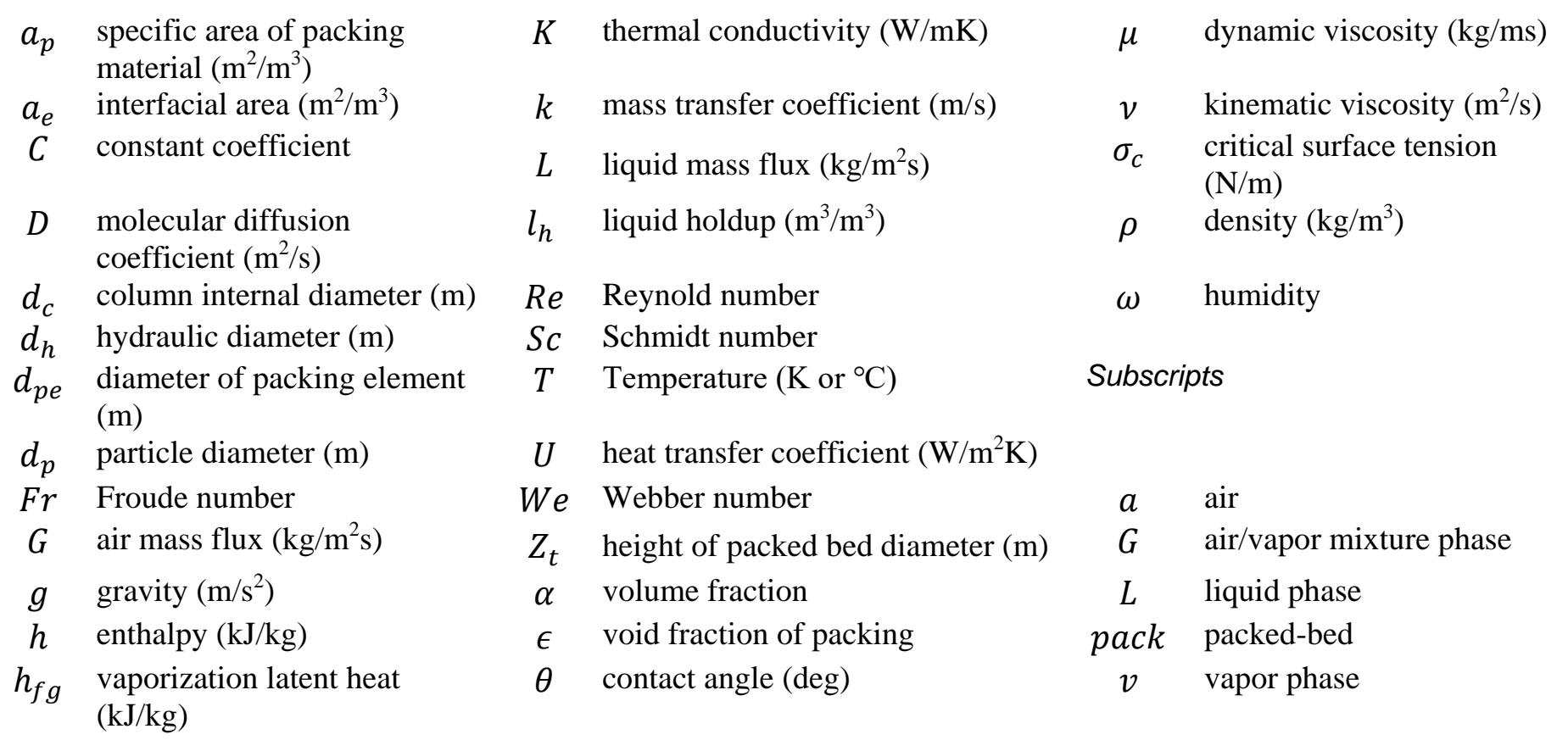

\section{Introduction}

The United Nations Environment Programme (UNEP) forecasts that the world will face a significant scarcity of fresh water by 2025 [2]. Humidification-dehumidification (HDH) with direct-contact packed bed material has been shown to be one of the most cost-effective approaches for water treatment and desalination. Major advantages of direct contact HDH are that it is cheap, it can be operated with low pressure losses and can use low-grade heat sources. The packed-bed material is the most important component of an $\mathrm{HDH}$ system; packed beds are also frequently used in chemical industries. 
HDH systems have been studied, amongst others, by Goosen et al. [3], El-Dessousky et al. [4], where they introduce a mathematical model validated by experiments. Most of the models are based on assuming film condensation. Alnaimat et al. [1], and Li et al. [5], developed a distinct mathematical model based on fundamentals of heat and mass transfer. Empirical correlations for mass transfer coefficient of liquid and air within the packed bed are used however in these models and this limits the range of suitable applications.

This study focuses on comparing several empirical correlations found in the literature. An experimental setup was built meticulously for validation of the computed results for a HDH with a packed bed provided by the company Lantec. Mass transfer coefficients are then calculated from several of the empirical correlations found in the literature. In the following, the experimental setup is first described, followed by the model used and its numerical implementation. Estimation of the mass transfer coefficients follows and their comparison with the experimental data is provided.

\section{Experimental Setup}

To comparatively study the mass transfer coefficients and interfacial area, an experimental device was set up for a direct contact condenser using a packed bed. Cooling water with temperature range of $20-22{ }^{\circ} \mathrm{C}$ was sprayed from the top with sprinklers. An "Aquatec" pump was placed to provide the condenser with the desired flow rate around $23 \mathrm{~g} / \mathrm{s}$ from a water tank to the condenser chamber made of CPVC pipe. The total height of CPVC pipe was $1 \mathrm{~m}$ and $0.5 \mathrm{~m}$ of its height was filled with packed-bed. The packed-bed was made of 3D regular array of square printed polycarbonate material. The specific area was $267 \mathrm{~m}^{2} / \mathrm{m}^{3}$. The packed-bed had an inner diameter of $0.14 \mathrm{~m}$ and its effective diameter was $17 \mathrm{~mm}$ when orientation was vertical. Other required properties of the packing material include the specific heat capacity is $1.12 \mathrm{~kJ} / \mathrm{kg} \mathrm{K}$, density of $1200 \mathrm{~kg} / \mathrm{m}^{3}$ and the void fraction is $87.8 \%$. Finally, inlet air was pushed through the packed bed. Two valves were used to control flow rate of air. Several type T-type thermocouples were used to measure temperatures at different locations of the condenser. To provide steam, a steam generator was utilized. To prevent heat loss from the setup, inlet of air vapor has been covered with insulation. A Labjack data acquisition system along with LabVIEW were used for the temperature measurements.

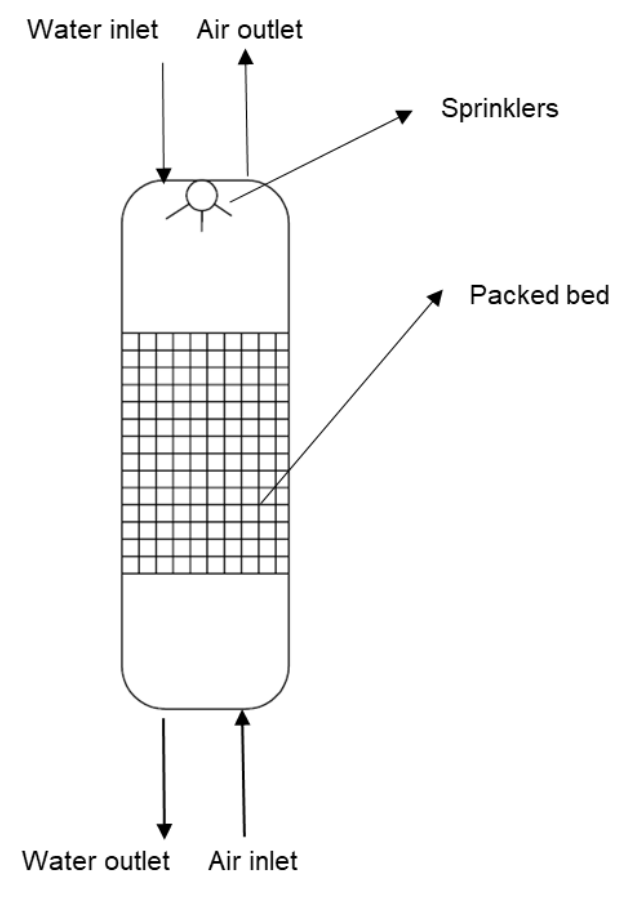

Fig. 1: Schematic Diagram of Direct Contact Counter Flow Condenser 


\section{Mathematical Model}

The mathematical model is developed by Alnaimat et. al [1] for direct contact packed-bed condenser is presented below. The important equations are provided in Eqs. (1) - (3)).

$$
\begin{gathered}
\frac{\partial T_{L}}{\partial t}=\frac{L}{\rho_{L} \alpha_{L}} \frac{\partial T_{L}}{\partial z}-\frac{\partial \omega}{\partial z} \frac{G\left(h_{f g}-h_{L}\right)}{\rho_{L} \alpha_{L} C p_{L}}+\frac{U a_{w}\left(T_{a}-T_{L}\right)}{\rho_{L} \alpha_{L} C p_{L}}+\frac{U_{L} a_{w}\left(T_{p a c k}-T_{L}\right)}{\rho_{L} \alpha_{L} C p_{L}} \\
\frac{\partial T_{a}}{\partial t}=\frac{-G}{\rho_{a} \alpha_{a}} \frac{\partial T_{a}}{\partial z}-\frac{\partial \omega}{\partial z} \frac{G\left(h_{f g}\left(T_{L}\right)-h_{v}\left(T_{a}\right)\right)}{\rho_{a} \alpha_{a} C p_{G}(1+\omega)}-\frac{U_{G}\left(a_{p}-a_{w}\right)\left(T_{a}-T_{p a c k}\right)}{\rho_{a} \alpha_{a} C p_{G}(1+\omega)}-\frac{U a_{w}\left(T_{a}-T_{L}\right)}{\rho_{a} \alpha_{a} C p_{G}(1+\omega)} \\
\frac{\partial T_{\text {pack }}}{\partial t}=\frac{1}{\rho_{\text {pack }} \alpha_{\text {pack }} C p_{\text {pack }}}\left(U_{G}\left(a_{p}-a_{w}\right)\left(T_{a}-T_{\text {pack }}\right)-U_{L} a_{w}\left(T_{\text {pack }}-T_{L}\right)\right)
\end{gathered}
$$

The overall heat transfer coefficient for gas and liquid is calculated through Eqs. (4)-(6):

$$
\begin{gathered}
U_{L}=k_{L}\left(\rho_{L} C_{P L} \frac{K_{L}}{D_{L}}\right)^{1 / 2} \\
U_{G}=k_{G}\left(\rho_{G} C_{P G}\right)^{1 / 3}\left(\frac{K_{G}}{D_{G}}\right)^{2 / 3} \\
U=\left(\frac{1}{U_{L}}+\frac{1}{U_{G}}\right)^{-1}
\end{gathered}
$$

The focus of this study is comparing various correlations for mass transfer coefficient and interfacial area and the possibility of validation with respect to experiment result for the direct contact packed-bed condenser. In this study, we considered mass transfer correlation developed by Onda et. al. (Eqs. (7) - (8)) [6], Van Krevelen et. al. (Eqs. (9) - (10)) [7], Shi et. al. (Eqs. (11) - (12)) [8], Billet et. al. (Eqs. (13) - (14)) [9], and Zech et. al. (Eqs. (15) - (16)) [10]. In addition, various correlation for interfacial area were investigated to see the impact of interfacial area value on the simulation's result. These correlations are suggested by Onda et. al. (Eq. (17)) [6], Puranik et. al. (Eq. (18)) [11], Kolev (Eq. (19)) [12], Bravo et. al. (Eq. (20)) [13], and Billet et. al. (Eq. (21)) [9]. These equations are mentioned below:

$$
\begin{gathered}
k_{L}=\frac{0.0051}{\left(a_{p} d_{p}\right)^{-0.4}}\left(\frac{\mu_{L} g}{\rho_{L}}\right)^{1 / 3}\left(\frac{\rho_{L} u_{L}}{a_{e} \mu_{L}}\right)^{2 / 3} S c_{L}^{-0.5} \\
k_{G}=c_{G}\left(\frac{D_{G}}{a_{p} d_{p}^{2}}\right)\left(\frac{\rho_{G} u_{G}}{a_{p} \mu_{G}}\right)^{0.7} S c_{G}^{1 / 3} \\
k_{L}=0.015 \frac{D_{L}}{\left[\frac{\mu_{L}^{2}}{\left(\rho_{L}^{2} g\right)}\right]^{1 / 3}\left(\frac{\rho_{L} u_{L}}{a_{e} \mu_{L}}\right)^{\frac{2}{3}} S c_{L}^{1 / 3}} \\
k_{G}=0.2 \frac{D_{G}}{d_{c}}\left(\frac{\rho_{L} u_{L}}{a_{p} \mu_{L}}\right)^{0.8} S c_{G}^{1 / 3}
\end{gathered}
$$




$$
\begin{aligned}
& k_{L}=0.86 \sqrt{\frac{6 D_{L}}{\pi d_{p e}}} \sqrt{\frac{u_{L}^{1.2} g^{1.3} \sigma_{L}^{0.3} \epsilon^{1.2}(1-0.93 \cos \theta)^{2}}{v_{L}^{1.4} \rho_{L}^{0.3} a_{p}^{2.4}}} \\
& k_{G}=c_{G} \frac{D_{G}}{d_{p e}}\left(\frac{\rho_{G} u_{G} d_{p e}}{\mu_{G}}\right)^{2 / 3} S c_{G}^{1 / 3} \\
& k_{L}=c_{L}\left(\frac{\rho_{L} g}{\mu_{L}}\right)^{1 / 6}\left(\frac{D_{L}}{d_{h}}\right)^{0.5}\left(\frac{u_{L}}{a_{p}}\right)^{1 / 3} \\
& k_{G}=c_{G} \frac{a_{p}^{0.5} D_{G}}{\sqrt{d_{h}\left(\epsilon-l_{h}\right)}}\left(\frac{\rho_{G} u_{G}}{a_{p} \mu_{G}}\right)^{3 / 4} S c_{G}^{1 / 3} \\
& k_{L}=c_{L} \sqrt{\frac{6 D_{L}}{\pi d_{p e}}}\left(\frac{\rho_{L} g d_{p e}^{2}}{\sigma_{L}}\right)^{-0.15}\left(\frac{u_{L} g d_{p e}}{3}\right)^{1 / 6} \\
& k_{G}=c_{G} \frac{D_{G}}{d_{p}} \frac{\epsilon+0.12}{\epsilon(1-\epsilon)^{-1}}\left(\frac{\rho_{G} u_{G} d_{p}}{(1-\epsilon) \mu_{G}}\right)^{2 / 3} S c_{G}^{1 / 3} \\
& a_{e}=a_{p}\left(1-\exp \left[-1.45\left(\frac{\sigma_{c}}{\sigma_{L}}\right)^{0.75} \operatorname{Re}_{L}^{0.1} \operatorname{Fr}_{L}^{-0.05} W e_{L}^{0.2}\right]\right) \\
& a_{e}=1.045 a_{p}\left(\frac{\rho_{L} u_{L}}{\mu_{L} a_{p}}\right)^{0.041}\left(\frac{\rho_{L} u_{L}^{2}}{\sigma_{L} a_{p}}\right)^{0.133}\left(\frac{\sigma_{c}}{\sigma_{L}}\right)^{0.182} \\
& a_{e}=0.583 a_{p}\left(\frac{\rho_{L} g}{a_{p}^{2} \sigma_{L}}\right)^{0.49}\left(\frac{u_{L}^{2} a_{p}}{g}\right)^{0.196}\left(a_{p} d_{p}\right)^{0.42} \\
& a_{e}=0.498 a_{p}\left(\frac{u_{L} \mu_{L}}{\sigma_{L}} \frac{6 \rho_{G} u_{G}}{a_{p} \mu_{G}}\right)^{0.392} \frac{\sigma_{L}^{0.5}}{Z_{t}^{0.4}} \\
& a_{e}=1.5\left(a_{p} d_{h}\right)^{-0.5}\left(\frac{\rho_{L} u_{L} d_{h}}{\mu_{L}}\right)^{-0.2}\left(\frac{\rho_{L} u_{L}^{2} d_{h}}{\sigma_{L}}\right)^{0.75}\left(\frac{u_{L}^{2}}{g d_{h}}\right)^{-0.45}
\end{aligned}
$$

\section{Computational Results and Comparison}

A finite differences scheme is used to solve the above system of equations. A second order approximation is used for the partial differences in Eqs. (1) - (3) for the whole domain. The quasi steady state assumption is used for simplification. A MATLAB program is developed to calculate various parameters used in the equations and solve the coupled non-linear ordinary differential equations.

\subsection{Mesh Independency}

As a first step, solver dependency on the grid resolution is investigated. Based on the Table 1 and the negligible change in outlet temperature for different grid resolution, simulation results are almost independent from the number of nodes. 
Table 1: Summary of mesh independence study performed for $\mathrm{L}=1.4 \mathrm{~kg} / \mathrm{m}^{2} \mathrm{~s}, \mathrm{G}=0.1 \mathrm{~kg} / \mathrm{m}^{2} \mathrm{~s}, \mathrm{~T}_{\mathrm{L}, \text { inlet }}=21^{\circ} \mathrm{C}$ and $\mathrm{T}_{\mathrm{a}, \text { inlet }}=68^{\circ} \mathrm{C}$

\begin{tabular}{|c|c|c|c|c|c|c|c|}
\hline & Nodes number & 51 & 101 & 201 & 51 & 101 & 201 \\
\hline Interfacial area correlation & Mass transfer coefficient & \multicolumn{2}{|c|}{ Liquid outlet temperature } & \multicolumn{2}{c|}{ Air outlet temperature simulation } \\
\hline Onda & Onda & 29.98 & 29.98 & 29.98 & 22.23 & 22.21 & 22.20 \\
\hline Onda & Van Krevelen & 29.10 & 29.10 & 29.10 & 34.75 & 34.74 & 34.73 \\
\hline Onda & Shi & 29.97 & 29.97 & 29.96 & 22.49 & 22.47 & 22.46 \\
\hline Onda & Billet & 29.97 & 29.97 & 29.97 & 22.41 & 22.39 & 22.39 \\
\hline Onda & Zech & 29.98 & 29.97 & 29.97 & 22.38 & 22.36 & 22.36 \\
\hline Bravo & Van Krevelen & 29.10 & 29.10 & 29.10 & 34.75 & 34.74 & 34.73 \\
\hline Puranik & Shi & 29.97 & 29.97 & 29.96 & 22.49 & 22.47 & 22.46 \\
\hline Kolev & Zech & 29.98 & 29.97 & 29.97 & 22.38 & 22.36 & 22.36 \\
\hline Billet & Billet & 29.97 & 29.97 & 29.97 & 22.41 & 22.39 & 22.39 \\
\hline
\end{tabular}

\subsection{Interfacial Area}

In order to investigate the effect of interfacial area on the resulting temperature, Eqs. (17) - (21) were used for interfacial area and Eqs. (7) - (8) was used for mass transfer coefficient. Fig. 2, shows variation in interfacial area across the packedbed. Interfacial area values change significantly depending on which correlation would be used; however, based on the values in Table 2, we can see that the outlet temperature are not affected by the change in the interfacial area value since the liquid and gas velocity are not that high.

Table 2: Outlet temperature values found for different interfacial area correlations

\begin{tabular}{|c|c|c|c|c|c|}
\hline Correlation & Average $\mathrm{A}_{\mathrm{w}}$ & $\begin{array}{c}\text { Liquid outlet temperature } \\
\text { simulation }\left({ }^{\circ} \mathrm{C}\right)\end{array}$ & $\begin{array}{c}\text { Difference } \\
\text { for liquid } \\
(\%)\end{array}$ & $\begin{array}{c}\text { Air Outlet Temperature } \\
\text { Simulation }\left({ }^{\circ} \mathrm{C}\right)\end{array}$ & $\begin{array}{c}\text { Difference } \\
\text { for air }(\%)\end{array}$ \\
\hline Onda & 126.99 & 29.985 & ---- & 21.654 & ---- \\
\hline Bravo & 4.37 & 29.984 & 0.003 & 21.663 & 0.040 \\
\hline Puranik & 81.91 & 29.985 & 0.003 & 21.652 & 0.051 \\
\hline Kolev & 27.45 & 29.985 & 0.001 & 21.653 & 0.006 \\
\hline Billet & 45.86 & 29.985 & 0.000 & 21.653 & 0.002 \\
\hline
\end{tabular}

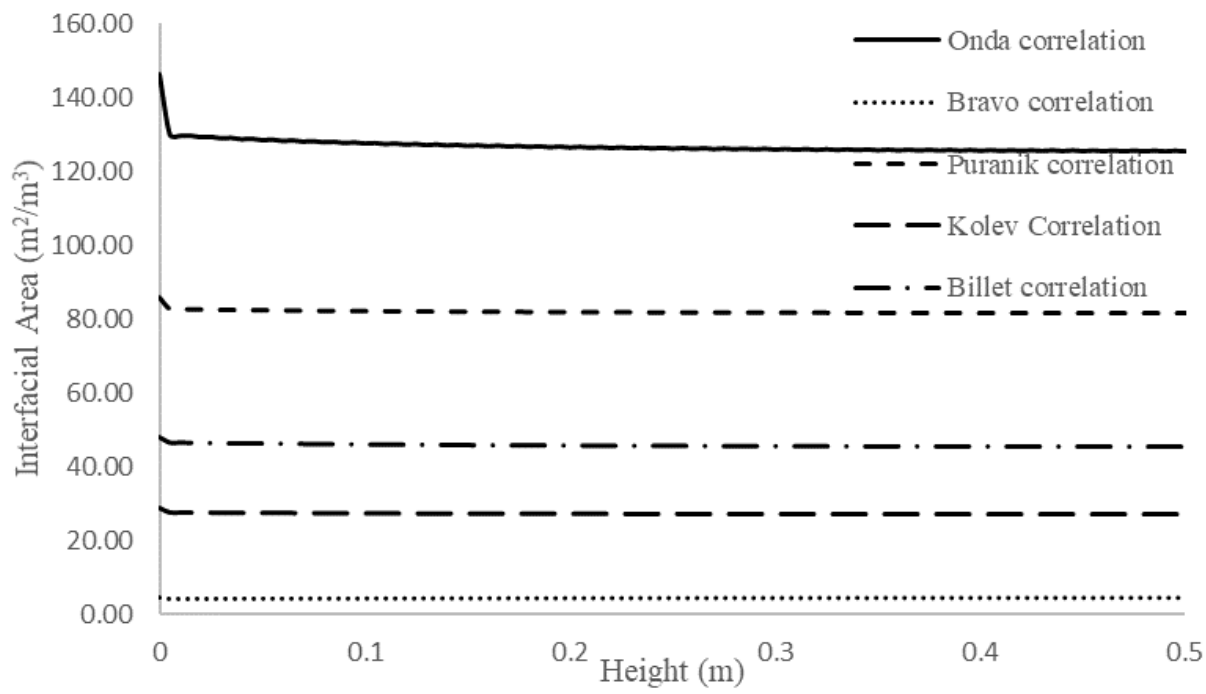

Fig. 2: Correlation predicts very different values of interfacial area for the packed-bed column. 


\subsection{Mass Transfer Coefficient}

When comparing simulation results with experiment, it can be noticed that Onda and Billet correlations predicts temperature of air (5\% error) and liquid (9\% error) more accurately in comparison with others. Furthermore, Shi and correlations aren't as precise as Onda's, but the error for these correlations is within 10\% range. Moreover, Fig. 3 depicts that Van Krevelen works better for around $50 \%$ of the experimental data for liquid, but there are significant errors someone makes use of the correlation to predict air temperature; this can be seen in Fig. 4. In addition, it can be observed that as the air temperature at the inlet increases, the error for predicting liquid temperature also rises. Among possible causes of error including having a non-uniform flow, water bridging, heat losses to environment for experimental setup, and misrepresentation of packed-bed geometry.

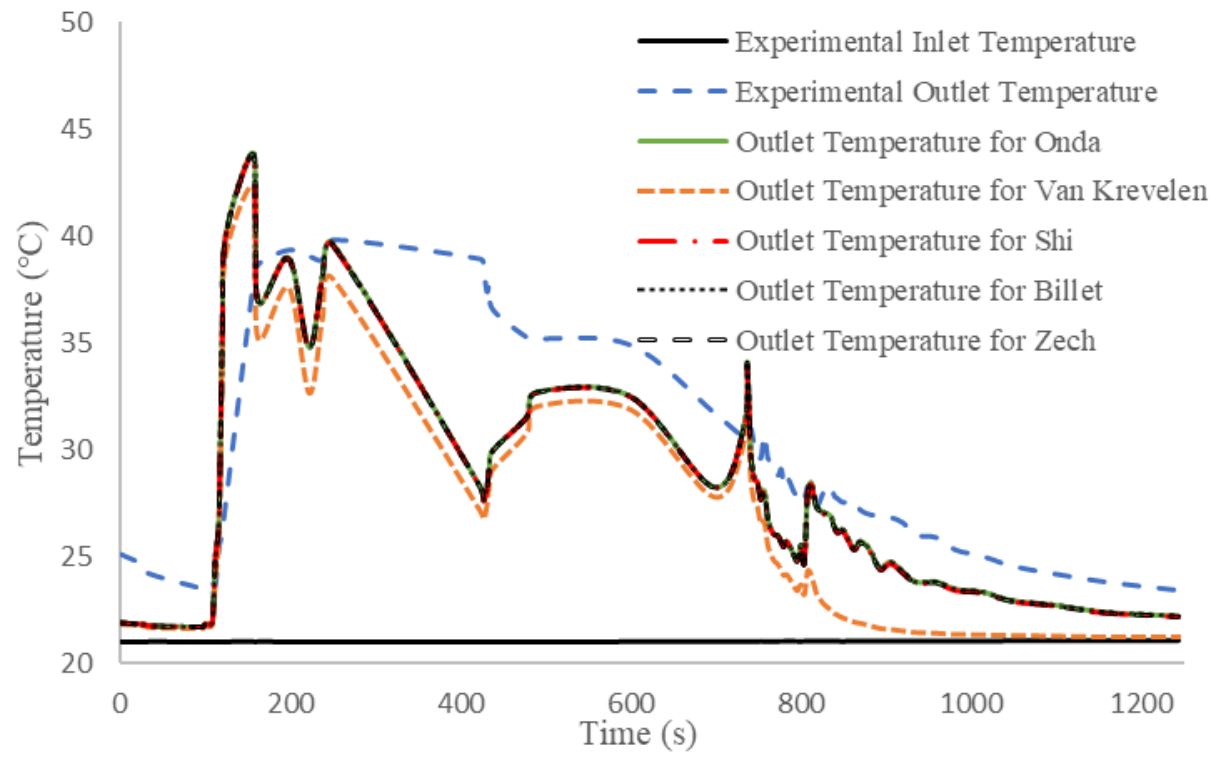

Fig. 3: Comparison of experimental data for different correlations for values of liquid outlet temperature obtained by varying the inlet air temperature (inlet temperature for water is constant). Most correlations predicted adequate measured values except for the Van

Krevelen correlation

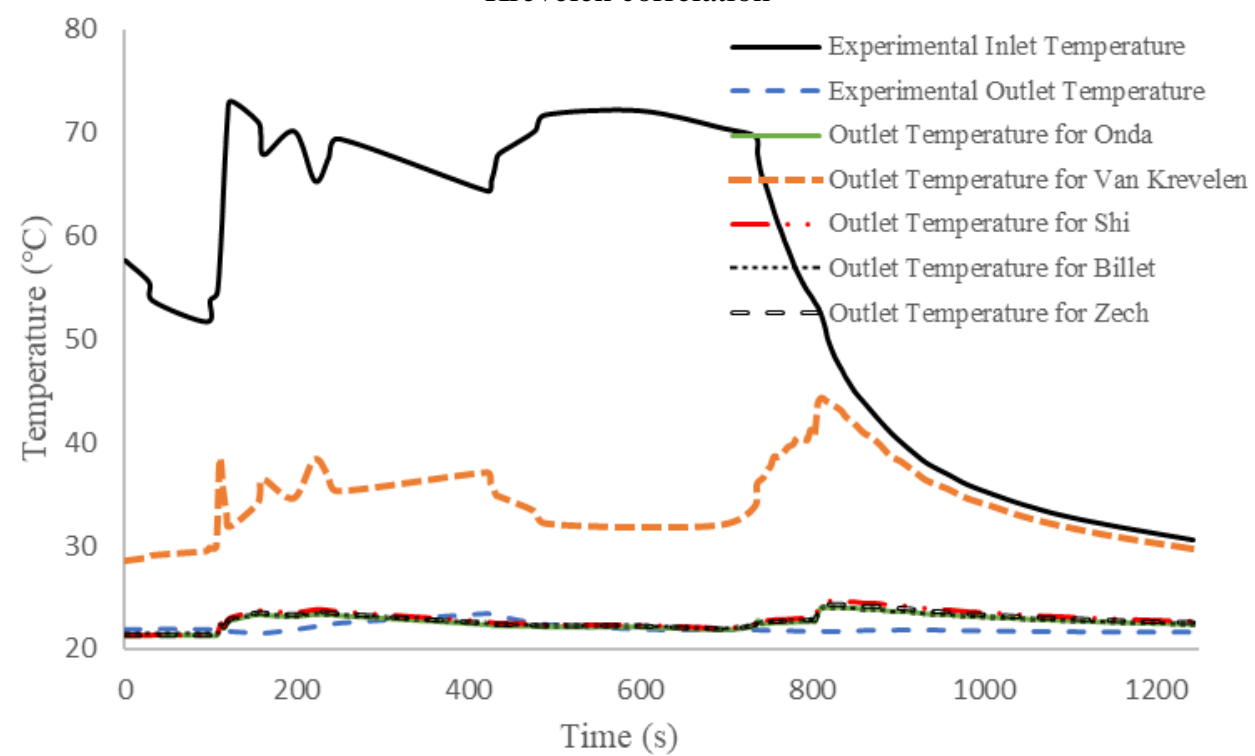

Fig. 4: Comparison of predicted outlet air temperature with experimental data for varying inlet air temperature. Most correlations predicted adequate measured values except for the Van Krevelen correlation 
Table 3: Average temperature error of gas and liquid for different mass transfer correlation

\begin{tabular}{|c|c|c|c|c|c|}
\hline & Onda & Van Krevelen & Shi & Billet & Zech \\
\hline \% Error for liquid & 9.39 & 14.65 & 9.49 & 9.40 & 9.45 \\
\hline \% Error for air & 5.15 & 68.00 & 6.59 & 5.42 & 6.10 \\
\hline
\end{tabular}

\section{Conclusion}

In this paper, a finite differences scheme was used to solve energy conservation for packed-bed condenser. The results obtained from the solver indicates that there is still a relative important uncertainty for the results obtained from considered correlations. Every correlation has a specific limit or range of validity. Also, it can be clearly stated that for the conditions considered, Onda and Billet correlations are the preeminent choices based on the experimental and comparative studies performed. The lack of fitted coefficient in the Van Krevelen coefficients and the need to fit data to the experiment for the other correlations, highlight the need for the validated coefficients for different packed-bed material microstructures and other parameters needed.

\section{Acknowledgements}

This paper is prepared with the support of ARPA-E (Advanced Research Projects Agency-Energy) of the department of energy under award no DE-AR0001000.

\section{References}

[1] F. Alnaimat, J. F. Klausner and R. Mei, "Transient analysis of direct contact evaporation and condensation within packed beds," International journal of heat and mass transfer, vol. 54, no. 15-16, pp. 3381-3393, 2011

[2] M. Shatat, M. Worall, and S. Riffat, "Opportunities for solar water desalination worldwide: Review," Sustainable Cities and Society, vol. 9, pp. 67-80, Dec. 2013, doi: 10.1016/j.scs.2013.03.004

[3] M. F. A. Goosen, S. S. Sablani, C. Paton, J. Perrat, A. Al-Nuaimi, I. Haffar, H. Al-Hinai, and W.H. Shayya "Solar energy desalination for arid coastal regions: development of a humidification-dehumidification seawater greenhouse," Solar Energy, vol. 75, no. 5, pp. 413-419, Nov. 2003, doi: 10.1016/j.solener.2003.07.007.

[4] H. T. A. El-Dessouky, "Humidification-dehumidification desalination process using waste heat from a gas turbine," Desalination, vol. 71, no. 1, pp. 19-33, Jan. 1989, doi: 10.1016/0011-9164(89)87055-9.

[5] Y. Li, J. F. Klausner, R. Mei, and J. Knight, "Direct contact condensation in packed beds," International Journal of Heat and Mass Transfer, vol. 49, no. 25-26, pp. 4751-4761, Dec. 2006, doi: 10.1016/j.ijheatmasstransfer.2006.06.013.

[6] K. Onda, H. Takeuchi, and Y. Okumoto, "Mass transfer coefficients between gas and liquid phases in packed columns," Journal of chemical engineering of Japan, vol. 1, no. 1, pp. 56-62, 1968

[7] D. Van Krevelen, and P. Hoftijzer, "Kinetics of simultaneous absorption and chemical reaction," Chemical Engineering Progress, vol. 44, no. 7, pp. 529-536, 1948

[8] M. G. Shi, and A. Mersmann, "Effective interfacial area in packed columns," International journal of heat and mass transfer, vol. 54, no. 15-16, pp. 3381-3393, 2011

[9] R. Billet, R and M. Schultes, "Predicting mass transfer in packed columns," German chemical engineering, vol. 8, no. 2, pp. 87- 96, 1985

[10] J. Zech, and A. Mersmann, "Liquid flow and liquid phase mass transfer in irrigated packed columns," in Proceedings of Institution Chemical Engineering Symposium Series, 1979, vol. 56, pp. 39.

[11] S. Puranik, and A. Vogelpohl, "Effective interfacial area in irrigated packed columns," Chemical Engineering Science, vol. 29 , no. 2, pp. 501-507, 1974

[12] N. Kolev, "Operational parameters of randomly packed-columns," Chemie Ingenieur Technik, vol. 48, no. 12, pp. 11051112,1976

[13] J. L. Bravo, and J. R. Fair, "Generalized correlation for mass transfer in packed distillation columns," Industrial \& Engineering Chemistry Process Design and Development, vol. 21, no. 1, pp. 162-170, 1982 